\title{
Addressing and measuring small business social responsibility in the African context: a stakeholder framework
}

\author{
Dennis Yao Dzansi, Senior Lecturer at the School of Entrepreneurship and Business \\ Development, Faculty of Management Science, Central University of Technology, \\ Bloemfontein, South Africa
}

Marius Pretorius, Associate Professor and Chair of Entrepreneurship in the Department of Business Management, Faculty of Economic and Management Sciences, University of Pretoria, Pretoria, South Africa

\begin{abstract}
Purpose - The aim of this paper is to provide a systematic and sound framework for addressing and measuring business social responsibility (BSR) in small and micro enterprises with specific focus on the African context.

Design/methodology/approach - The paper is theoretical but has practical applications. The approach was to use principles of BSR from the literature to create a framework for addressing BSR issues in smaller ventures that operate in the African environment. Developing the framework involved operationalizing the linguistic meaning of BSR into observable indicators for it to be measurable. This involved the breaking down of the concept of BSR into dimensions and eventually into measurable elements.
\end{abstract}

Findings - The framework identifies customer-, employee-, and community-related issues as the key BSR activities of African small businesses. Environmentalism is not a major concern for most of these businesses because they are mostly retail and services in nature; hence their impact on the environment will be so low that they need not concern themselves with environmental issues.

Research limitations/implications - Critics will point out the absence of environmental issues as a major limitation. However, the authors believe that such activities are typically associated with large industrial ventures. Thus, given their nature, it is unlikely small businesses will concern themselves with such activities.

Originality/value - There is a need for a framework that captures the African context. This paper fulfils that need by proposing a framework for micro and small ventures with possible inclusion of medium enterprises based on the stakeholder theory. Academics will find it useful in their research efforts. Fund managers will also find it useful as a tool for evaluating small business BSR performance. Small business owners will have a benchmark in performing their social obligations. Finally, consumers, businesses, citizens, NGOs and society at large can use it in distinguishing credible and effective socially responsible SMMEs from those that are not. 


\section{Introduction}

Although a vast amount of work has been done on the society versus business relation, it is disturbing to note that the social responsibility of small businesses (BSR) in the African context remains under explored. In our view, questions such as, what are the most likely BSR activities for smaller businesses that operate in Africa or how do smaller businesses that operate in Africa perceive and apply BSR, remain unanswered precisely because of the absence of a framework and measurement instrument that captures the essence of small business BSR in the African context. Thus, researchers, policy makers, and small business people in Africa are forced to use unsuitable frameworks, measurement instruments, and tools designed for elsewhere. There is therefore a need for a framework that captures the African context. This paper fulfils that need by proposing a framework for micro and small ventures with possible inclusion of medium enterprises based on the stakeholder theory.

Though somewhat controversial, there is little doubt that businesses acknowledge the importance of BSR (Garriga and Mele, 2004, p. 51). Today several informal measures exist to evaluate and inform stakeholders of public companies about their BSR status. There are even fund managers who compile investment funds based on BSR. The social responsibility of business is not a new concept either. Cannife (2005, p. 6) suggests that BSR is not a choice anymore. In fact, considerable dialogue on the subject still exists. But as noted by researchers such as Wilson (1980); Thompson and Hood (1993); Van Marrewijk (2003) and Valor (2005), most of the empirical studies to date have focused on large businesses.

Thus, although much work has been done on the society versus business relation, the issue of the social responsibility of small business, especially those that operate on the African context remains a mirage. This is perhaps because most of the studies to date have mainly focused on corporate or large organizations. However, with the increasing understanding that smaller firms play significant (if not more) roles in the economic and social lives of most countries (Dzansi, 2004, p. 54; Lepoutre and Heene, 2006, p. 3), attempts are being made to study the concept, focusing exclusively on small businesses. Sadly, the pace of research on BSR in small businesses in the African context is disappointing.

However, this should not be surprising because BSR research even in big business in the African context is scant. Visser points out that only about 20 percent of all developing countries have had any BSR articles published with South Africa dominating and pockets coming from Mali, Zambia, Kenya, Nigeria, and Côte d'Ivoire. In a more detailed analysis, Visser points out that only 12 out of Africa's 53 countries have had any research published in core BSR journals with 57 percent focusing on South Africa, and 16 percent on Nigeria. Even in the case of South Africa, Visser notes that most of these articles are not socially oriented.

This apparent bias against small businesses in general and small businesses in the African context in particular is likely to create problems. Firstly, the bias in favor of large business suggests that social responsibility is not really a small business issue. Not surprisingly the concept is often referred to as "corporate social responsibility" (CSR). In this paper, we prefer the term "business social responsibility" (BSR) because it does not carry any big business connotation. This study, however, is concerned with small and micro businesses that are typical 
to most African countries. The typical size would be one to five workers (but up to 50) and \$1020,000 per annum (up to \$30,000).

Second, because of the glaring apathy towards small businesses BSR research in Africa, questions such as what are their most likely BSR activities, do they understand and apply BSR, and if so, do they really benefit from its application remain unanswered. Our literature search did not reveal any prior study that has addressed these questions. A sound framework that captures the essence of small business BSR in the African context is therefore imperative to answer such questions. Our study primarily proposes a framework for addressing small business related BSR issues in Africa based on the proposition that there is a difference between BSR for small and large businesses on the one hand and that even in small businesses BSR is not the same and differs from place to place.

The United Nations Industrial Development Organization (Unido) has observed that in the few studies that compared the BSR of larger enterprises with that of smaller ones, the smaller enterprises scored lower (Unido, 2005). However, it warned that this might only reflect a lack of formal policies and BSR language, and not necessarily the absence of BSR. The Commission of the European Communities (2002, p. 11) has also observed that small ventures often manage their social impact in a more intuitive and informal manner. These observations indicate that the standards by which larger and smaller enterprises are compared are unfair to small enterprises. This difference means that if any meaningful assessment and comparison of BSR performance is to be done, then BSR activities specific to smaller enterprises need to be identified. For that we need an appropriate framework.

\section{The need for a framework for the African context}

Visser is unrelenting in arguing that, compared to other regions, Africa lags far behind in the BSR research, especially in respect to small businesses. The dearth of BSR research in the African context creates a number of problems. One obvious problem is that, there are no frameworks to guide research and policy in terms of small business/BSR in the African context. This is in stark contrast to what happens in other places especially in the Western world.

In countries such as Canada, the UK, and the USA, just to mention a few, numerous empirical research has been done on the small business/BSR interface. This has led to the development of context specific frameworks for the phenomenon in these places. In Spain for example, there is what is called the "Catalan social responsibility framework" for small businesses. Similarly, Canada, UK and many others have got their own frameworks that guide their social responsibility agenda.

Unfortunately, these foreign frameworks might not be helpful in the African context, mainly because as Visser points out, BSR is not the same everywhere across the globe as different cultures affect how consumers expect businesses to behave. Moreover, the BSR agenda challenges of developing countries are different from those of the developed world. The interpretation of BSR might therefore differ between the European countries and those of Africa. In fact, Visser points out that existing frameworks produced for use in the developed countries do not fully (if at all they do) take the African context into consideration. He argues that the 
European and American frameworks and metrics are unsuitable for the developing world and more specifically Africa, where customs and beliefs dictate what activities businesses are likely to engage in. Consequently, there is a need to conduct empirical research in the developing country context in order to identify the challenges, frameworks, and metrics applicable to the African context.

The main aim of this paper is therefore to identify from the literature, the dimensions and elements of BSR relevant for small and micro ventures that operate in the rural parts of Africa. Such a model will be useful for both practitioners and researchers alike. It will give practitioners a framework to direct their strategies and develop scorecards for measurements of the BSR strategy impact.

\section{Conceptualizing BSR}

As noted by Jones (1999, p. 163), a plethora of definitions of BSR exist. Three of these reflect the essence of the concept:

1. BSR refers to business's obligation to seek socially beneficial results along with economically beneficial results in its policies, decisions and actions (Kyambalesa, 1994, p. 201).

2. BSR is the continuing commitment by business to behave ethically and contribute to economic development while improving the quality of life of the workforce and their families as well as of the local community and society at large (World Business Council for Sustainable Development (WBCSD), 2001).

3. BSR is a company's commitment to operating in an economically and environmentally sustainable manner while recognizing the interest of its stakeholders. Stakeholders include investors, customers, employees, business partners, local communities, the environment, and society at large (Peyton, 2003).

These definitions, like many others, emphasize that in pursuing economic interests, managers of businesses (irrespective of size) need to be conscious of the needs of other stakeholders besides their shareholders, because these people are capable of impacting positively or negatively on the primary business objective of increasing shareholder wealth. For example, businesses need to treat their workers in a humane and fair manner; they need to satisfy their customers; they also need to pursue the well-being of the communities in which they transact their businesses and protect the environment for the purpose of sustainable production.

Second, in defining BSR as they do, the proponents of BSR seem to argue that it is only fair on the part of businesses to compensate those who are affected by their activities (stakeholders). However, managers need to ensure that the activities of these stakeholders do not negatively affect the economic outcome of the business. How could they achieve this without developing lasting positive relations with stakeholders? Would not fair trading practices, humane treatment of their workers, and contributing to local community improvement develop lasting positive relations with the stakeholders? There are numerous examples of businesses that have benefited from this philosophy. An example is Happy Computers, a small British computer company. According to Business in the Community (BITC), Happy Computers has for the last three years 
been rated one of the top three information-technology training companies in the UK. According to BITC (2005), Happy Computers owes its success to motivated and empowered staff, ensuring work/life balance as a key priority for everyone, limiting adverse environmental impact, supporting and encouraging staff to work fully paid one day a month for a charity of their choice, and instituting a time-bank of 100 days which can be claimed for projects that bring "mutual benefit”.

Third, the common thread running through these definitions of BSR is the reference to meeting both the societal expectations and realizing the shareholder objectives in combination with the pure profit motive as the "ultimate" goal of business.

In view of the above, BSR is operationally defined for this study as: a venture's commitment to operating in an economically sustainable manner while at the same time recognizing the interests of its other stakeholders (customers, employees, business partners, local communities, society at large) over and above those provided by law. This means that mandatory activities that businesses engage in fall outside the definition. The implication is that meeting legal requirement is not really being socially responsible. At best, it can only mean being ethical (ethically responsible).

\section{Dimensions, elements and benefits of BSR}

Although several BSR elements are apparent, the literature identifies consumerism (Thompson and Smith, 1991; Longenecker et al., 2000; Gillis and Spring, 2001); employee relations (Scarborough and Zimmerer, 1996; Kuratko and Hodgetts, 2001; Gillis and Spring, 2001), and community relations (Thompson and Hood, 1993; Gillis and Spring, 2001) as the three main categories under which BSR activities of small ventures can be grouped. Each is briefly explored to benefit the reader.

\subsection{Consumerism (or customer relation) activities}

This means responsible customer relations. Dorian (1996) argues that it is only when a business practices good customer care that it can be assured of continued business operation. Thus customers are the most important stakeholder group of any business (Kyambalesa, 1994; Scarborough and Zimmerer, 1996, p. 83; Longenecker et al., 2000, p. 369). According to Longenecker et al. (2000, p. 369) and Gillis and Spring (2001), consumerism is about honest advertising, product safety, reliable and durable products, fair pricing, customer after-care and politeness towards customers. These authors point out that small firms are naturally attracted to consumerism because they have a strong natural flexibility in meeting those needs. For example, small business owners have close relationships with their customers and thus are able to understand their needs. Thompson and Smith (1991) concur that customer satisfaction is a primary focus of small ventures. Customer satisfaction today requires more than durable, dependable, and honest advertising; it also implies good customer care practices (Dzansi, 2004, p. 87) that requires active participation of dependable employees (Dorian (1996) in Dzansi, 2004, p. 87). 


\subsection{Employee- or workforce-related activities}

Scarborough and Zimmerer (1996, p. 68) argue that few other stakeholders are as important to a business as its employees. Hence an important BSR issue is the kind of relationship that exists between a business and its employees. It is often argued that employees have a big impact on other key stakeholders, such as customers. The extent to which customers trust a business is likely to be influenced by the impression created by its human face: the workers. A disgruntled worker could easily communicate his negative attitude to customers. Small ventures are more vulnerable in this respect and it is generally accepted that workers in small ventures are closer to customers, since most of the employees are often recruited from the communities from which their customers come. Therefore, the crucial question is: how does the business deal with its employees?

According to Kuratko and Hodgetts (2001, p. 160), a firm's main social responsibility issues relating to employees include: promotion of employee health and safety; remedial education for disadvantaged employees; employee training and development; and child day-care facilities for working parents. In addition, Scarborough and Zimmerer (1996, p. 69) consider respect for employee opinion; involvement of employees in decision making; and rewarding employees adequately as important social obligations to their employees that small business managers should meet. According to Gillis and Spring (2001), employees and potential employees are concerned about wages, benefits, health, safety, training and advancement opportunities.

Of the above, employee health and safety, employee training and development, child day-care facilities for working parents and fair and above minimum wages appear to be areas that small ventures would probably focus on given the general poor communities they function in. Because of the well documented "Ubuntu" concept, an African philosophy that requires a person to be the others keeper, we argue that in accordance with this philosophy, more often than not, employees of small businesses will be close relatives or recruited from the local community. Thus local community issues become important BSR activities for small businesses in Africa.

\subsection{Community-related activities}

According to Gillis and Spring (2001), the community forms the largest and most visible stakeholder group of any business. As mentioned earlier, this group is often defined as local for small ventures. Community concerns for BSR, according to the same authors, include charitable giving and local employment. Thompson and Hood (1993, p. 1) point out that charitable contribution is an important indicator of the social performance of small ventures. In a study in Canada, Martin, as quoted in Thompson and Hood (1993), found that as a group, small businesses donated higher levels of their pre-tax income than the larger businesses. Thus, it would appear that charitable donations (which can take many forms) and local employment form two of the most important small-business BSR activities in their local communities. Miller and Katz sum up the importance of community involvement when they wrote:

Organizations need to have a strategy to help build sustainable local and national communities in which to do business. Many organizations are stepping up to the challenge of becoming socially responsible, both as a strategic need-to be known in the community as a good place to work, thus becoming a magnet for talent-and to be differentiated in the market place. 
Put differently, BSR must be seen as a business strategy (Philips, 2006, p. 23). That is, a business needs to be regarded as socially responsible so as to create a positive image in the community it trades in, so that, it can among other things, attract and retain world class employees, and be perceived by customers, investors and suppliers as "special”. Thus, from a strictly business point-of-view, BSR provides a strategic management tool for gaining and maintaining sustainable competitive advantage.

From the African point-of-view, the argument can be somewhat different. It is fair to say that businesses, especially the small ones in African countries, should be attracted to BSR because of the scale of social needs that still prevail in these regions, the failure of governments to provide for these needs (Philips, 2006, p. 23), and the often assumed ability of small businesses in dealing with social problems relative to the larger businesses. Fostering BSR among small businesses in Africa in order to bring about social transformation besides the business case, is therefore imperative.

Thus far, customer, employee, and community-related activities appear to be the most relevant BSR focus of small ventures. Bearing in mind the environmental (socio-cultural) dichotomies of the developed world and Africa, it becomes apparent that a framework that focuses on these three key stakeholders whilst identifying key activities relevant to the African context is imperative for small business to impact on the communities they trade in as well as for their own long term survival. In other words, despite the inconclusive evidence to confirm the business case for small business BSR performance, we proposition that benefits do accrue to both owners and other stakeholders when businesses irrespective of size engage in BSR practices - a voluntary societal activity.

\subsection{Benefits of BSR}

Significant benefits can accrue to both businesses and their stakeholder groups if businesses conduct their affairs in a socially responsible manner (Van Marrewijk, 2003, p. 97). Organizations such as Unido (2002) and the International Institute for Sustainable Development (IISD) (2002) identify improved financial performance and increased sales as direct business benefits for firms that engage in BSR. These may result from lower operating costs, enhanced brand image and easier access to capital. Several empirical studies have since confirmed the positive correlation between financial performance and BSR. Orlitzky (2001), Kilkenny et al. (1999), and Besser (1999) confirmed through their studies that community support, due to BSR, was the single most important factor associated with small business performance. These are termed business benefits.

According to the IISD (2002) the most important community benefits are charitable contributions, employee volunteer programs in the communities, business involvement in programs such as education and local employment, and product safety. As mentioned above, Kuratko and Hodgetts (2001, p. 160) and Scarborough and Zimmerer (1996, p. 69) identify employee health and safety, employee training and development, child day-care facilities for working parents, and fair living wages as typical employee benefits. The IISD (2002) suggests that BSR can further lead to product safety and quality, and better product durability and functionality, which are typical consumer benefits. Similarly Longenecker et al. (2000, p. 369) 
and Gillis and Spring (2001) argue that BSR leads to consumer benefits such as honest advertising, product safety, reliable and durable products, fair pricing, customer after-care and politeness towards customers that means consumers will get value for their money. BSR therefore appears to have indirect benefits that are not easily related to direct benefits such as sales and profits (Dzansi, 2004, p. 212).

In summary, this discussion has led to the identification of stakeholder theory as a foundation for studying BSR, but not disregarding the shareholder and societal approach discussed by Van Marrewijk (2003). The core elements of BSR therefore include: commitment to operating in an economically sustainable manner and recognition of the interests of stakeholders. The theoretical foundation helped to identify employees, customers, and the local communities as the key stakeholders of small ventures and not only the shareholders. At the same time, shareholders require profits, customers require safe, good quality, durable, functional, and fairly priced products and employees require healthy and safe working environments with fair and living wages, and they value training and development. Local communities value local employment, charitable contributions, and employee volunteer programs. The extent to which these expectations are simultaneously met provides a basis for assessing a small business's BSR performance and the impact thereof. Figure 1 demonstrates the breakdown of BSR as a concept and serves as a conceptual model to guide the paper. We now discuss the stakeholder theory as a foundation for studying and practicing BSR.

\section{Stakeholder theory as a foundation of BSR}

Investigating BSR, Donaldson and Preston (1995, p. 68) explored conceptions of the firm and came to the conclusion that: two models of the firm exist: the "input-output" model and the "stakeholder" model. The input-output model is generally economically aligned, while the stakeholder model is social-duty aligned. These conclusions would imply two opposing perspectives of the firm: economic versus stakeholder perspectives. However, we believe that economic and stakeholder views are not necessarily opposing views. This paper supports the stakeholder model of the firm, with the belief that the stakeholder perspective actually incorporates the economic goals of the firm. In addition, the stakeholder theory provides a foundation for studying BSR, thus laying the theoretical basis for the construction and empirical testing of a measuring instrument for BSR in small ventures. This paper forms part of a larger study that investigated the social responsibilities of SMMEs in a rural part of South Africa. The paper is theoretical and proposes a conceptual framework for small business BSR (stakeholder theory, meaning of BSR, activities of BSR, and benefits of BSR).

A major portion of the BSR paradigm focuses on the role of managers of small ventures in promoting social responsibility, as managers are acknowledged to be the key decision makers. For BSR to be really effective, it has to be part of the overall business strategy. However, as the main risk bearers, venture managers usually have the power and ability to determine the extent of BSR in their ventures. Thus, venture managers need to have a clear, convincing, and unambiguous understanding of this concept. Determining the theoretical foundation of BSR is considered the appropriate starting point because this could help venture managers to understand and value the reasoning behind BSR and therefore create the so-called "buy-in" to the concept. 


\subsection{Stakeholders, their stakes, and influence}

Two main schools of thought are easily identifiable in the society versus business relation debate. Firstly, as Kohls and Christensen (2002, p. 223) note, there are people who regard businesses as entities separate from society. As such, they believe in the separation of the wealth creation and distribution functions of a business, often arguing that through their wealth-creation activities, businesses already fulfill their social mandate. This view suggests that businesses have no social obligations other than the ones they owe to their shareholders. Therefore, being in business is fulfilling the social obligation of business (Kohls and Christensen, 2002, p. 223).

The second school of thought, as exemplified by Hobel (2002), believe that businesses form an integral part of society and that both society and business have reciprocal influences on each other that can be positive or negative. They argue that when a business maximizes its positive impact on the communities in which it conducts its operations, it will in turn elicit maximal positive impact from community members on the business concerned. This view perhaps led McCline and Gilinsky (1998) to conclude "Businesses have a social contract with society at large", meaning that there are others besides shareholders to whom businesses owe obligations.

This perspective implies a multi-stakeholder approach to managing a business, in which the various stakeholders' interests are simultaneously taken care of in order to create a win-win situation. That is, the shareholders become richer and the other stakeholders become more satisfied. So what does "stakeholder" mean? Who are the stakeholders of a business and what are their stakes and influences? This question is especially relevant for the small business sector, especially when small business is hailed as the key vehicle for economic growth.

Laczniak and Murphy (1993) describe stakeholders as persons or groups of people that have or claim ownership rights or interests in a venture's activities. Such rights, these authors argue, result from actions or transactions by the firm. They classify stakeholders as primary or secondary: In their view primary stakeholders are those without whose continuing participation the business cannot proceed as a going concern. Typically, primary stakeholders of a business include investors (shareholders), employees, customers, government, communities and suppliers. The secondary stakeholders are those who can influence or affect, or are influenced or affected by, the firm but are not engaged in transactions with the firm. They are not essential for its survival but can cause significant harm to the firm (Laczniak and Murphy, 1993). Because of their obvious importance to small businesses, this study focuses mainly on the primary stakeholders.

The management literature describes several stakeholders interested in the activities of business, including owners, customers, employees, local communities, suppliers, the environment, and the like. Reed (2002) provides an incisive discourse in this respect. According to him, each stakeholder group has certain relationships with the firm and also have normative claims or rights that they can make on the firm, and if these are granted they can lead to greater total utility or a larger "common good". 
Reed (2002) draws the following conclusions from his analysis:

- all the primary stakeholders have economic stakes in the firm; and

- their claims are based on fair economic activity, i.e. the firm's activities contribute to a "common good" of the society.

For example, shareholders' main claim would be ownership right of fair economic opportunity, i.e. to make profit. Likewise, employees would have an economic stake in the firm's prosperity so that the firm could provide for their safety, a humane working environment and a living wage. Consumers' economic stake in the firm might be to have access to a wide range of competitively priced, safe, reliable products and services. Although Reed (2002) does not explicitly make the point, similar arguments can be made for local communities, since customers and employees of small ventures usually come from the local communities.

In addition to economic stakes, stakeholders other than shareholders might have a claim to what Reed (2002, p. 178) calls “authenticity”. He regards stakeholders' claim to "authenticity” as business's identification with local communities by operating within them. Thus he states, there is some sense in asking businesses to support local community values and initiatives (Reed, 2002, p. 178).

Based on this analysis, it is fair to conclude that all the primary stakeholders of businesses, whether small or large, have economic stakes in the venture. It could therefore be argued that the stakeholder view of the firm does not really contradict the economic view; instead it appears to encompass the economic view. Thus, in line with the Swedish International Development Agency (SIDA) (2005, p. 5) observation that BSR is defined differently by different stakeholders, we proceed from the premises that the stakeholder theory provides a sufficient foundation upon which BSR can be studied among African small businesses and micro enterprises.

\section{Methodology}

Our approach was to use principles of BSR as described in the literature to create a framework for addressing BSR related issues in smaller ventures for the developing country context. Developing the framework involved operationalizing the variables identified in the literature for measurement. The linguistic meaning of BSR was operationalized into observable indicators in order for it to be measurable. In this regard and based on the literature reported earlier, Sekaran's (1992, p. 152) method (see Figure 1) that involves the breaking down of a concept into dimensions and eventually into measurable elements was employed. The elements E1, E2, and E3 were identified as possible questionnaire items (see Figure 1).

\section{The framework}

Our framework consists of three dimensions namely: community involvement, consumerism, and employee relations, elements of the dimensions and outcomes to stakeholders and shareholders. These dimensions represent the three key stakeholders identified for small businesses that operate in rural parts of Africa (Dzansi, 2004, p. 89). 


\subsection{Dimension 1 (D1) - Community involvement}

Community involvement dimension include contributions to community causes, and the amount of money (expressed as a percentage of pre-tax profit) spent on social causes. The use of percentages is preferred for research purposes because as is well-known, small business owners for obvious reasons do not like to divulge actual figures.

\subsection{Dimension 2 (D2) - Consumerism (customer relations)}

For customer relations and loyalty issues, the elements identified included elements such as: how promptly the business reacts to their customer complaints, how politely they deal with customers, how honest they are in their marketing, and most importantly how committed they are to customer satisfaction. These elements are important to win and retain a loyal customer base that is crucial for the success of small ventures.

\subsection{Dimension 3 (D3) - Employee relations}

To ascertain the extent to which small ventures relate to their employees, information on certain key labor issues are required. Included in our framework are health care provision, absence of child labor, employee benefits, and freedom to choose the amount of overtime work.

\subsection{Outcomes (benefits)}

As mentioned earlier, if executed well, BSR could lead to improved financial performance as a result of high employee morale, lower employee turnover, increased employee productivity and customer loyalty. Biographic items that measure outcomes/benefits of BSR - expected or perceived, as well as observed improvements in employee morale, employee turnover, employee productivity and customer loyalty. The proposed model recommends sales growth, gross profit growth, and the amount contributed towards BSR activities measured as a percentage of pre-tax profit. Such interventions are typically associated with the following possible outcomes for the stakeholders: reduced local unemployment; community improvement; community contributions as a percentage of gross profit; social and economic inclusion; social cohesion in the community; customer satisfaction; job satisfaction; skills development; employability; and work/life balance.

In summary, our framework, as depicted in Figure 1, identifies community, consumer/customer and employees as the three most important external and internal stakeholders because they form the primary stakeholders (besides the owners) of any business whose issues must be of priority on the BSR agenda for small businesses that operate in Africa. These primary stakeholders have practical issues that affect their quality of life. We call these issues elements. For each stakeholder group and respective country or society, owner/managers can identify key issues that are likely to be most valued by the stakeholders and then devote resources, both financial and non financial, to meet them. The expectation is that beneficiaries (stakeholders) will reciprocate by patronizing (in the case of customers and local community) and showing more commitment to the business (in the case of employees). In the end, all the stakeholders, including owners, gain in the form of outcomes - the last component of the framework. 


\section{Implications for managers}

Our framework provides several advantages. First, the framework is proposed to serve as a guideline for planning interventions of a socially responsible nature among small businesses in the African context. We take the cue from van der Woerd and van der Brink (2004, p. 174) who observed that the European Corporate Sustainability Framework (ECSF) and the Traditional Balanced Scorecards are too generic to be of any use to a wide spectrum of companies and opine that even with these authors developing the so called responsive business scorecard (RBS), the extant frameworks are still either too generic (do not take the special needs of small businesses that operate in rural Africa into consideration) or too ambitious in terms of their scope to be of any real use to small businesses in the African context. Our framework overcomes this difficulty by paving the way for practitioners (owner/managers, researchers, and policy makers) in Africa to structure the performance and measurement of BSR activities and the impact thereof on SMMEs and society to cover only a few but critical business success factors.

From a theoretical point-of-view, our framework in our opinion, provides a simple to understand and implement yet relevant tool for addressing and measuring small business BSR performance. Its simplicity lies in the focus on only three, but very important stakeholders of firms irrespective of size - employees, the local community, and the customers who have direct impact on the business performance. Of course, the ambitious firms can add other dimensions such as environmental issues, supply chain issues and many others to the model if they so wish.

By restricting SMME BSR to only a few but very important stakeholders of the firm, it becomes much easier for owner/managers to focus their attention and scarce resources on groups that are critical to the success of their firms without having to overstretch their resources over too many activities just because others do so. The three dimensions - community, employee, and customers in our opinion, form the most important stakeholders of the firm that owner/managers cannot afford to ignore when they pursue their BSR agenda.

We agree with the widely held view that the three dimensions of our framework - community, employee, and customers, are the most important stakeholders of small businesses. It is therefore assumed that most if not all owner/managers of small businesses are not only familiar with the issues and needs of these stakeholders, but will prioritize them in their social responsibility agenda. The framework therefore provides a more objective tool for benchmarking and assessing performance or non-performance of BSR in SMMEs.

From a research point-of-view, the three dimensions namely, community involvement, customer and employee orientations, appear both separate and overlapping to some extent. Because of the nature of social responsibility there are interrelations between the dimensions. As previously pointed out, good customer care practices require active participation of dependable employees and employees of small businesses will be close relatives or recruited from the local community. Thus local community issues become important BSR activities for small businesses in Africa, thereby suggesting interrelations between the dimensions. 


\section{Conclusions, limitations and recommendations for future research}

The paper has given direction to the underlying dimensions of BSR activities that should be pursued in addressing and measuring BSR in small and micro businesses in the rural African context. The dimensions of BSR in small ventures seem to have a stronger focus on the human aspects. The inclusion of outcomes/benefits in the framework is a clear indication of our belief that there are benefits associated with BSR for both business and society; and that owner/managers go about performing socially responsible activities expecting certain rewards.

Critics may be quick to point out the absence of environmental issues such as waste dumping and biosphere protection as a major limitation. Confirming our initial believe that such activities are typically associated with large industrial ventures; such issues were not identified in the empirical research that is presented in a follow-up article. It appears that survival and growth issues are paramount in the mind of the small venture manager and environmental issues are rather an issue for government and legislation. Thus, given their nature, it is unlikely that small businesses will concern themselves so much with such activities. From the point of view of micro and small businesses, it seems that the inclusion of environmentalism as a dimension in the framework may turn out frivolous. Of course, the inclusion of environmentalism would make the framework more generalizable as it will make it applicable to medium enterprises because of their size. It also points to a potential "flaw in the perception" of small business regarding the social responsibility concept. However, this was not an objective for this study and this may call for future research to observe the differences that exist between developed and under developed countries.

Finally, practitioners are invited to scrutinize the model for practical application. The question that arises is: Why do small businesses engage in BSR practices? Would the reasons for engagement shed light on why environmental issues are not part of the model? At this point we want to boldly proposition that BSR engagement by small ventures are purely done for one reason only - a tangible economic benefit, whether directly or indirectly perceived by such ventures. Not any different from big business. The focus and depth however appears very different. 


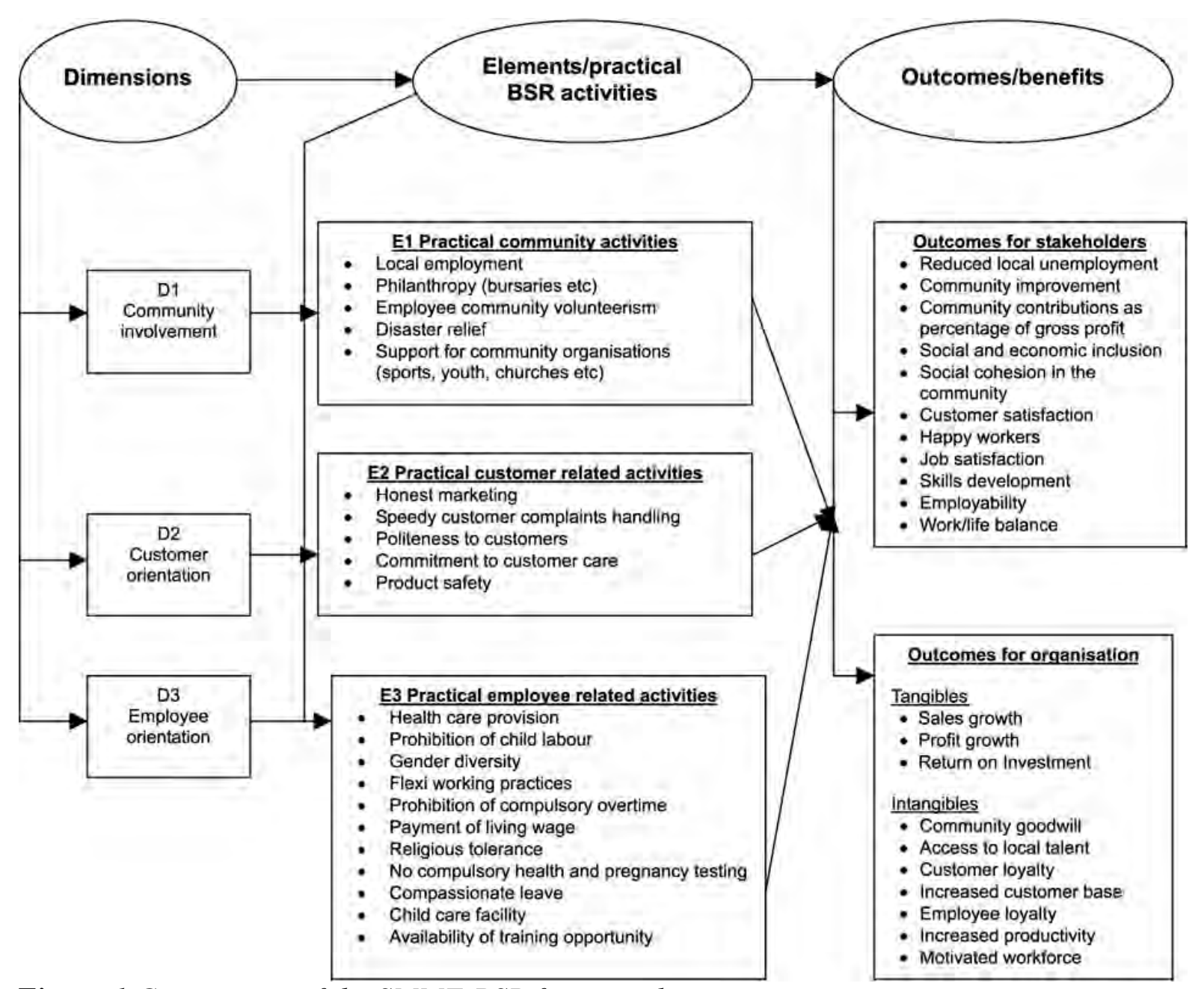

Figure 1 Components of the SMME-BSR framework

\section{References}

Besser, T.L. (1999), "Community involvement and perception of success among small business operators in small towns", Journal of Small Business Management, Vol. 37 No.4, pp.16-29.

Business in the Community (BITC) (2005), "Happy Computers - impact on society: Awards for Excellence 2003 - Impact on Society Awards (small company)", available at:

www.bitc.org.uk/resources/case_studies/happy_computers.html.

Cannife, M. (2005), "Corporate social responsibility", Accountancy Ireland, Vol. 37 No.1, pp.69.

Commission of the European Communities (2002), Corporate Social Responsibility: A Business Contribution to Sustainable Development, Commission of the European Communities, Brussels, 
Donaldson, T., Preston, L.E. (1995), "The stakeholder theory of the corporation: concepts, evidence, and implications", Academy of Management Review, Vol. 20 No.1, pp.65-91.

Dorian, P. (1996), Intensive Customer Care: Competitive Strategies for South African Companies, Zebra Press, Johannesburg.

Dzansi, D.Y. (2004), "Social responsibility of SMMEs in rural communities", unpublished PhD thesis, University of Pretoria, Pretoria.

Garriga, E., Mele, D. (2004), "Corporate social responsibility", Journal of Business Ethics, Vol. 53 pp.51-71.

Gillis, T., Spring, N. (2001), "Doing good is good for business", Communication World, Vol. 18 No.6, pp.23-7.

Hobel, J. (2002), "Should companies have a conscience?", Canadian HR Reporter, February 24, p. 9.

International Institute for Sustainable Development (IISD) (2002), "Corporate social responsibility", available at: www.bsdglobal.com/issues/sr.asp.

Jones, M.T. (1999), "The institutional determinants of social responsibility", Journal of Business Ethics, Vol. 20 pp.163-79.

Kilkenny, M., Nalbarte, L., Besser, T. (1999), "Reciprocated community support and small town small business success", Entrepreneurship and Regional Development, Vol. 11 pp.231-46.

Kohls, J., Christensen, S.L. (2002), "The business responsibility for wealth distribution in a globalized political economy: merging moral economics and Catholic social teaching", Journal of Business Ethics, Vol. 35 pp.223-34.

Kuratko, D.F., Hodgetts, R.M. (2001), Entrepreneurship: A contemporary Approach, 5th ed., Harcourt College Press, Orlando, FL.

Kyambalesa, H. (1994), Success in Managing a Small Business, Avebury Ashgate, Aldershot. Laczniak, G.R., Murphy, P.E. (1993), Ethical Marketing Decisions: The Higher Road, Allyn \& Bacon, Boston, MA.

Lepoutre, J., Heene, A. (2006), "Investigating the impact of firm size on small business social responsibility: a critical review", working paper, Ghent University, June, available at: www.feb.ugent.be (accessed 19 June 2008).

Longenecker, J.G., Moore, C.W., Petty, J.W. (2000), Small Business Management: An Entrepreneurial Emphasis, 11th ed., South-Western College Publishing, Cincinnati, $\mathrm{OH}$. 
McCline, R.L., Gilinsky, A. (1998), "Socially responsible entrepreneurial ventures as macro culture", available at: www.babson.edu/entrep/fer/papers98.

Orlitzky, M. (2001), "Does firm size confound the relationship between corporate social performance and firm financial performance?", Journal of Business Ethics, Vol. 33 No.2, pp.167-80.

Peyton, K. (2003), "CSR: who needs it?", available at: www.cbsr.bc.ca.

Philips, F. (2006), "Corporate social responsibility in an African context", The Journal of Corporate Citizenship, Vol. 24 pp.23-7.

Reed, D. (2002), "Employing normative stakeholder theory in developing countries: a critical theory perspective", Business and Society, Vol. 41 No.2, pp.166-207.

Scarborough, N.M., Zimmerer, T.W. (1996), Effective Small Business Management, 5th ed., Prentice-Hall, Upper Saddle River, NJ.

Sekaran, U. (1992), Research Methods for Business: A Skill Building Approach, 2nd ed., Wiley, New York, NY.

Swedish International Development Agency (SIDA) (2005), "Guidelines for SIDA's support to corporate social responsibility", Department for Infrastructure and Economic Cooperation, available at: www.sida.se/publications.

Thompson, J.K., Hood, J.N. (1993), "The practice of corporate social performance in minorityversus non-minority-owned small business", Journal of Business Ethics, Vol. 12 pp.197-206.

Thompson, J.K., Smith, H.L. (1991), "Social responsibility and small business: suggestions for research", Journal of Small Business Management, Vol. 29 No.1, pp.30-44.

United Nations Industrial Development Organization (Unido) (2002), "Corporate social responsibility and developing country SMMEs", available at: www.unido.org/doc/330817.htmls.

Valor, C. (2005), "Corporate social responsibility and corporate citizenship: towards corporate accountability", Business and Society Review, Vol. 110 No.2, pp.191-212.

Van der Woerd, F., Van der Brink, T. (2004), "Feasibility of a responsive business scorecard: a pilot study", Journal of Business Ethics, Vol. 55 pp.173-86.

Van Marrewijk, M. (2003), Concepts and definitions of CSR and corporate sustainability: between agency and communion", Journal of Business Ethics, Vol. 44 pp.95-105.

Wilson, E. (1980), "Social responsibility of small business: what are the small business perspectives?", Journal of Small Business Management, Vol. 18 No.3, pp.17-24. 
World Business Council for Sustainable Development (WBCSD) (2001), "Corporate social responsibility: making good business sense", WBCSD, Washington, DC, available at: www.wbscd.org •

\section{About the authors}

Dennis Yao Dzansi is a Senior Lecturer in Entrepreneurship, Strategic Management, Financial Management and Research Methods at the School of Entrepreneurship and Business Development, Faculty of Management Science, Central University of Technology, Bloemfontein, South Africa. Dennis Yao Dzansi is the corresponding author and can be contacted at: ddzansi@cut.ac.za

Marius Pretorius is an Associate Professor in Strategy, Department of Business Management, University of Pretoria, South Africa. He is a turnaround and growth strategy consultant. He has published several academic articles on entrepreneurship and turnaround. 